\title{
Hypersomnolence among Adolescents: Narcolepsy an Often Misdiagnosed Condition
}

\author{
${ }^{1}$ Zia Hashim, ${ }^{2}$ Loveleen Mangla, ${ }^{3}$ Garima Shukla, ${ }^{4}$ Anupama Gupta, ${ }^{5}$ Alok Nath, ${ }^{6}$ Ravi Mishra
}

\begin{abstract}
Hypersomnolence is becoming an important problem in adolescents because of the change of lifestyle. Narcolepsy is a chronic and incurable sleep disorder, classically presenting with excessive daytime sleepiness associated with cataplexy, hypnagogic hallucinations, sleep paralysis and nocturnal sleep fragmentation. It's most common presenting symptom and essential feature is excessive daytime sleepiness. Diagnosis is often missed in India because of lack of proper sleep labs and training to diagnose this disorder

This case highlights the need to keep Narcolepsy among the common differentials for adolescents presenting with excessive daytime sleepiness, while also looking for other common causes of the same. A detailed approach to the same is also discussed.
\end{abstract}

Keywords: Adolescent, Hypersomnolence, Multiple sleep latency test, Sleep, Type II narcolepsy.

How to cite this article: Hashim Z, Mangla L, Shukla G, Gupta A, Nath A, Mishra R. Hypersomnolence among Adolescents: Narcolepsy an Often Misdiagnosed Condition. Indian J Sleep Med 2017;12(3):49-52.

\section{Source of support: Nil}

Conflict of interest: None

\section{INTRODUCTION}

Narcolepsy is a chronic and incurable sleep disorder, classically presenting with excessive daytime sleepiness associated with cataplexy, hypnagogic hallucinations, sleep paralysis, and nocturnal sleep fragmentation. Its most common presenting symptom and essential feature is excessive daytime sleepiness.

While narcolepsy is a common disorder in Western populations, it is confined to few case series in India. ${ }^{1-4}$ Its incidence among children has risen during the outbreaks

\footnotetext{
${ }^{1,3}$ Assistant Professor, ${ }^{2}$ Senior Resident, ${ }^{4}$ Sleep Disorder Specialist, ${ }^{5}$ Additional Professor, ${ }^{6}$ Research Scientist

1,2,5,6 Department of Pulmonary and Sleep Medicine, Sanjay Gandhi Post Graduate Institute of Medical Sciences, Lucknow Uttar Pradesh, India

${ }^{3,4}$ Department of Neurology, All India Institute of Medical Sciences, New Delhi, India

Corresponding Author: Alok Nath, Additional Professor Department of Pulmonary and Sleep Medicine, Sanjay Gandhi Post Graduate Institute of Medical Sciences, Lucknow, Uttar Pradesh, India, Phone: +919616606668, e-mail: draloknath@ gmail.com
}

of H1N1 infection, especially in China. ${ }^{5}$ While the usual age at onset of symptoms is second or third decade of life, onset during the second decade can be associated with unique diagnostic challenges, since a number of sleep-related problems are extremely common at this age, mainly insufficient sleep, poor sleep hygiene and, circadian rhythm sleep disorder-delayed sleep phase type.

This case highlights the need to keep narcolepsy among the common differentials for adolescents presenting with excessive daytime sleepiness, while also looking for other common causes of the same. A detailed approach to the same is also discussed.

\section{CASE REPORT}

A13-year-old male student of 9th class, with normal birth and development history, presented with complaints of excessive daytime sleepiness of nearly 3 years duration, in the form of naps especially in the classroom, which persisted despite adequate nighttime sleep. He reported feeling a sudden onset of an urge to sleep and would sleep off anywhere and in any condition, e.g., in the classrooms, on the playground, while writing, etc. If he would be allowed to take a nap for about an hour, at such times, he would feel refreshed. His Epworth sleepiness scale (ESS) score was 12 . He also complained of not feeling refreshed on waking up in the morning.

He also reported 3 to 4 times of nocturnal awakenings after sleep onset and would take 15 to 20 minutes to sleep off again. He had a history of possibly disturbed sleep since childhood. There was no history of hypnagogic or hypnopompic hallucinations, sleep paralysis, or any definite history suggestive of cataplexy. On probing, he did report some episodes of abnormal sensation in his head, while laughing loudly and his face used to look sleepy during those episodes. He would occasionally laugh during sleep around midnight.

At the same time, the patient reported a number of depressive symptoms, with a feeling of worthlessness, inability to focus on studies well, and deteriorating scholastic performance over the last 1 year. He reported that despite putting in an effort, he was unable to get the desired results in his school exams. He did report multiple issues of poor sleep hygiene.

There was no history to suggest chronic sleep deprivation, sleep apnea, parasomnia, depression, and medicinal 
abuse. He had been a mouth breather and had a history of drooling of saliva during sleep. He had a history of head trauma at the age of 1 year associated with vomiting and a squint in one eye following which a soft boggy swelling was present over his occipital region, and the magnetic resonance imaging (MRI) of head was normal. A family history of snoring and asthma was present.

On examination, he was found to be nonobese, with a body mass index of $22.71 \mathrm{~kg} / \mathrm{m}^{2}$. He did have a large tongue with a Mallampati classification of 4 .

Based on the clinical presentation and ruling out any history of illicit drug abuse, few clinical diagnoses were entertained. The first possibility kept was of inadequate sleep hygiene and resultant dysthymic condition. A presumptive possibility of narcolepsy without cataplexy (type II) and/obstructive sleep apnea was also kept. Whole-night diagnostic attended polysomnography (PSG) and a multiple sleep latency test (MSLT) were performed.

Level I nocturnal PSG was conducted with ALEX system. Sleep measures and respiratory measures were collected and scored according to the American Academy of Sleep Medicine criteria. ${ }^{6}$ During the 405 -minute recording period, his sleep efficiency was $93 \%$. Sleep stages were unremarkable, with the exception of slightly increased percent N1 (19\%). His sleep architecture was unremarkable. Rapid eye movement (REM) latency was 11.5. Apnea Hypopnea Index (AHI) was $<5$ with no limb movements. An MSLT, consisting of five naps conducted 2 hours apart and starting 3 hours after his morning wake-up time, showed sleep on three naps with an average sleep latency of 3 minutes (normal 10 minutes).

Four of the five naps were positive for sleep-onset REM (SOREM).

Polysomnography and MSLT were repeated at a higher center. Important observations are tabulated in Table 1. His hematological and biochemical profiles were normal. Thyroid function tests were also normal. The MRI of the brain did not reveal any abnormality.

Human leukocyte antigen (HLA) typing was carried out and revealed that our patient was positive for HLADQB1*06:02.

Patient and family members were counseled and prescribed sleep hygiene, oral modafinil $200 \mathrm{mg}$ once a day, in the morning, and scheduled naps for 15 to 20 minutes during the daytime. On 1-year follow-up, the patient was $>70 \%$ better and follow-up ESS was 3, taking only one nap postlunch and his scholastic performance also improved. On 2-year follow-up, the patient was doing the same and now taking two brief naps during the day in school.

\section{DISCUSSION}

Narcolepsy remains an often misdiagnosed condition due to variation in clinical presentation and the number

\begin{tabular}{lll}
\multicolumn{3}{c}{ Table 1: PSG and MSLT parameters } \\
\hline PSG parameters & $\begin{array}{l}\text { SGPGI, } \\
\text { Lucknow }\end{array}$ & $\begin{array}{l}\text { AlIMS, } \\
\text { Delhi }\end{array}$ \\
\hline Total sleep time (minutes) & 405 & 472 \\
Sleep efficiency (\%) & 95.6 & 91.05 \\
Arousal index (number of arousal & 9.9 & 13.7 \\
events/hour of sleep) & & \\
WASO (minutes) & 35 & 21 \\
$\begin{array}{l}\text { AHI (event/hour of sleep) } \\
\text { RERA index (number of RERA }\end{array}$ & 2.1 & 1.54 \\
events/hour of sleep) & 0 & 12.2 \\
$\begin{array}{l}\text { Desaturation index (number of } \\
\text { oxygen desaturation/hour of sleep) } \\
\text { PLM index (number of PLM }\end{array}$ & 0.4 & 0 \\
movements/hour of sleep) & 0 & \\
MSLT parameters & & 0 \\
Number of naps with SOREMs & $2 / 4$ & $4 / 4$ \\
Mean sleep latency & 2 minutes \\
Mean REM latency & 4 minutes & 5 minutes \\
& 35 seconds & 52 seconds \\
\hline
\end{tabular}

WASO: Wake after sleep onset; RERA: Respiratory effort related arousal; PLM index: Periodic limb movements index; SGPGI: Sanjay Gandhi Post Graduate Institute of Medical Sciences; AlIMS: All India Institute of Medical Sciences

of social environmental conditions which may preclude pointed reporting by patients. The estimated prevalence in the Western world is $0.05 \%,{ }^{7}$ but there are no prevalence data from Indian population. There are only few case series and individual reports published from India. Bhatia and Arif ${ }^{8}$ and Gupta et $\mathrm{al}^{1}$ had reported a 30-yearold and a 37-year-old male patient respectively; both of them have been symptomatic since childhood in India. Gupta et $\mathrm{al}^{2}$ have reported a case series of 20 patients with mean age of 25 , two among which presented at a very early age of 8 and 11 years respectively. One of them had cataplexy, while the other did not have cataplexy at presentation. Similarly, Sureshbabu et $\mathrm{al}^{3}$ have also reported 13 cases with a mean age of 23.5 , among which two were very young at the time of presentation-14 and 15 years respectively. Among many series, the median age of onset of narcolepsy is 16 years, $, 9,10$ but it remains undiagnosed for several years. This can be due to multiple reasons like lack of awareness among patients and clinicians alike, lack of specific biomarkers, and associated comorbid sleep disorders and/or neuropsychiatric illnesses. This patient currently being reported was 15 years old at presentation and had the onset of symptoms around the age of 11 years.

\section{Narcolepsy Misdiagnosis among Adolescents}

Apart from some genetic disorders and common childhood sleep conditions like obstructive sleep apnea and restless legs syndrome, sleep remains undisturbed among the majority of children. However, around the stage of adolescence, especially in urban populations with easy 
access to gadgets and other nighttime activities, the prevalence of disturbed sleep among adolescents has been steadily rising across the globe. ${ }^{11}$

Narcolepsy underdiagnosis and overdiagnosis are both problems that clinicians need to address. In addition, the overlap between pediatric and adult care for this population poses a major challenge in the early targeted management of various problems affecting this specific population.

Since sleep hygiene begins to deteriorate around this stage of life due to multiple factors, including intrinsic hormonal factors and more importantly behavioral choices that have become common among teenagers the world over, inadequate sleep hygiene and insufficient sleep syndrome remain a major cause of excessive daytime sleepiness among adolescents. Many studies have shown a significant gap between the average sleep times required for adolescents $v s$ the average total time spent sleeping over a 24-hour cycle. ${ }^{12}$ This aspect should be the first to be addressed by physicians taking care of these patients, for which a detailed sleep history, close rapport establishment, and counseling remain central to offering solutions to improve sleep and reduce daytime sleepiness. The problem becomes more complex with the resultant impact on daytime performance in studies, behavior, interpersonal interactions and relationships, among others. Juvenileonset mood disorders, either resulting from inadequate sleep or appearing de novo (especially in case of positive family history) always needs to be looked for, identified, and treated accordingly. The other common problem is the appearance of circadian rhythm sleep disorders of the delayed sleep onset type. Since the incidence of this condition is highest at this age, it can easily be missed and unless a detailed sleep history with the clear focus on morningness-eveningness and close review of 2 to 3 week sleep logs is carried out, this diagnosis can be missed and patients may be diagnosed as narcolepsy.

On the contrary, clinicians with a low threshold for diagnosis of common primary sleep disorders, especially sleep apnea, may not entertain the diagnosis of narcolepsy for long. While type I PSG laboratory are not commonly available, home studies are conducted commonly in urban areas and often these are carried out without adequate individualized planning, with the sole objective of diagnosing and quantifying sleep apnea. The MSLT is evidently not carried out for most patients. In this scenario, despite seeking timely help, many patients of this age group might be diagnosed with mild sleep apnea (which is certainly common), treating which may certainly not help in reducing daytime sleepiness.

Even in the presence of episodes of cataplexy, misdiagnosis of the episodes as epileptic seizures, presyncope, or other conditions is not uncommon. Cataplexy among children and adolescents can have varied presentations, and knees, head, and jaw are the most frequently compromised body segments, eyelids, arms, and trunk being less commonly involved. ${ }^{13}$ More rarely, blurred vision, slurred speech, irregular breathing, or a sudden loss of smiling mimics have been reported, due to which the term "cataplectic-facies" was coined and the usual triggering emotions, such as laughter, joking, or anger, may or may not be present, especially when close to an abrupt onset. So, the description of a sleepy face during laughter was a quite likely cataplexy in our patient.

In the current report, the patient did have multiple issues which could have accounted for the daytime hypersomnolence. Individually addressing each of them and basing comprehensive treatment strategies on them helped to improve his sleep and resultant quality of life significantly.

The American Academy of Sleep Medicine's International Classification of Sleep Disorders, 3rd edition ${ }^{3}$ reclassified narcolepsy as divided into two types of presence/absence of cataplexy. Our patient belongs to type II. Type I narcolepsy is associated with low $(<110$ $\mathrm{mg} / \mathrm{dL}$ ) cerebrospinal fluid hypocretin (orexin-A) levels, although these can be normal in type II narcolepsy. ${ }^{14}$ This could not be performed for the reported patient due to nonavailability of the facility. HLA-DQB1*06:02 haplotypes are associated with 93 and 56\% in types I and II narcolepsy respectively. ${ }^{15}$ Our patient was positive for HLA-DQB1*06:02.

Treatment is required lifelong, but narcolepsy is very much manageable using both nonpharmacological measures like improvement in sleep hygiene and timed naps during afternoon, as well as pharmacological treatment like methylphenidate, amphetamines, and modafinil/ armodafinil for the somnolence, tricyclic antidepressants, or selective serotonin reuptake inhibitors or serotoninnorepinephrine reuptake inhibitors for cataplexy or sodium oxybate for overall management. With customized management, patients usually lead meaningful and productive personal and professional lives. This was evident in the patient being reported in the current article.

\section{CONCLUSION}

Narcolepsy is a chronic sleep disorder often beginning to present, but diagnosed uncommonly during adolescence, especially in the Indian subcontinent. Early identification can go a long way to help improve sleep and associated quality of life of these individuals.

\section{REFERENCES}

1. Gupta R, Goel D, Farney R, Walker J. Narcolepsy: a case from India with polysomnographic findings. Neurol India 2012 Jan-Feb;60(1):79-81. 
2. Gupta A, Shukla G, Goyal V, Srivastava A, Behari M. Clinical and polysomnographic characteristics in 20 North Indian patients with narcolepsy: a seven-year experience from a neurology service sleep clinic. Neurol India 2012 Jan-Feb;60(1):75-78

3. Sureshbabu S, Muniem A, Bhatia M. Diagnosis and management of narcolepsy in the Indian scenario. Ann Indian Acad Neurol 2016 Nov;19(4):456-461.

4. Patnaik SK, Raju U, Garg A. Childhood narcolepsy- a rare disorder. Indian J Pediatr 2013 Jul;80(7):611-612

5. Partinen $\mathrm{M}$, Saarenpaa-Heikkila $\mathrm{O}$, Ilveskoski I, Hublin $\mathrm{C}$, Linna M, Olsén P, Nokelainen P, Alén R, Wallden T, Espo M, et al. Increased incidence and clinical picture of childhood narcolepsy following the $2009 \mathrm{H} 1 \mathrm{~N} 1$ pandemic vaccination campaign in Finland. PloS One 2012 Mar;7(3):e33723.

6. Medicine AAoS. The international classification of sleep disorders, revised: diagnostic and coding manual. Westchester (IL): American Academy of Sleep Medicine; 2014

7. Majid H, Hirshkowitz M. Therapeutics of narcolepsy. Sleep Med Clin 2010 Dec;5(4):659-673.

8. Bhatia M, Arif MA. Narcolepsy an often missed diagnosis: first documented case from India. Neurol India 2009 JulAug;57(4):509-511.

9. Dauvilliers Y, Montplaisir J, Molinari N, Carlander B, Ondze B, Besset A, Billiard M. Age at onset of narcolepsy in two large populations of patients in France and Quebec. Neurology 2001 Dec;57(11):2029-2033.

10. Okun ML, Lin L, Pelin Z, Hong S, Mignot E. Clinical aspects of narcolepsy-cataplexy across ethnic groups. Sleep 2002 Feb;25(1):27-35.

11. LeBourgeois MK, Hale L, Chang AM, Akacem LD, Montgomery-Downs HE, Buxton OM. Digital media and sleep in childhood and adolescence. Pediatrics 2017 Nov;140(Suppl 2): S92-S96

12. Hasler BP, Soehner AM, Clark DB. Circadian rhythms and risk for substance use disorders in adolescence. Curr Opin Psychiatry 2014 Nov;27(6):460-466.

13. Serra L, Montagna P, Mignot E, Lugaresi E, Plazzi G. Cataplexy features in childhood narcolepsy. Mov Disord 2008 Apr;23(6):858-865.

14. Bourgin P, Zeitzer JM, Mignot E. CSF hypocretin-1 assessment in sleep and neurological disorders. Lancet Neurol 2008 Jul;7(7):649-662.

15. Mignot E, Lammers GJ, Ripley B, Okun M, Nevsimalova S, Overeem S, Vankova J, Black J, Harsh J, Bassetti C, et al. The role of cerebrospinal fluid hypocretin measurement in the diagnosis of narcolepsy and other hypersomnias. Arch Neurol 2002 Oct;59(10):1553-1562. 